\title{
Trypanosoma cruzi infection: a continuous invader-host cell cross talk with participation of extracellular matrix and adhesion and chemoattractant molecules
}

\section{A.P.M.P. Marino ${ }^{1}$, A.A. Silva ${ }^{1}$, R.T. Pinho ${ }^{2}$ and J. Lannes-Vieira ${ }^{1}$}

\author{
${ }^{1}$ Laboratório de Autoimunidade e Imuno-regulação, and \\ ${ }^{2}$ Laboratório de Imunologia Clínica, Departamento de Imunologia, \\ Instituto Oswaldo Cruz, Fiocruz, Rio de Janeiro, RJ, Brasil
}

\section{Correspondence \\ J. Lannes-Vieira \\ Departamento de Imunologia \\ Instituto Oswaldo Cruz, Fiocruz \\ Av. Brasil, 4365 \\ 21045-900 Rio de Janeiro, RJ \\ Brasil \\ E-mail: lannes@ioc.fiocruz.br}

Presented at SIMEC 2002

(International Symposium

on Extracellular Matrix),

Angra dos Reis, RJ, Brazil,

October 7-10, 2002.

Research supported by CAPES, CNPq, FAPERJ and PAPES-II-Fiocruz.

Received January 10, 2003 Accepted February 21, 2003

\begin{abstract}
Several lines of evidence have shown that Trypanosoma cruzi interacts with host extracellular matrix (ECM) components producing breakdown products that play an important role in parasite mobilization and infectivity. Parasite-released antigens also modulate ECM expression that could participate in cell-cell and/or cell-parasite interactions. Increased expression of ECM components has been described in the cardiac tissue of chronic chagasic patients and diverse target tissues including heart, thymus, central nervous system and skeletal muscle of experimentally T. cruzi-infected mice. ECM components may adsorb parasite antigens and cytokines that could contribute to the establishment and perpetuation of inflammation. Furthermore, $T$. cruzi-infected mammalian cells produce cytokines and chemokines that not only participate in the control of parasitism but also contribute to the establishment of chronic inflammatory lesions in several target tissues and most frequently lead to severe myocarditis. T. cruzi-driven cytokines and chemokines may also modulate VCAM-1 and ICAM-1 adhesion molecules on endothelial cells of target tissues and play a key role in cell recruitment, especially of activated VLA $-4{ }^{+} \mathrm{LFA}-1^{+} \mathrm{CD} 8^{+}$ $\mathrm{T}$ lymphocytes, resulting in a predominance of this cell population in the inflamed heart, central nervous system and skeletal muscle. The VLA-4 ${ }^{+}$-invading cells are surrounded by a fine network of fibronectin that could contribute to cell anchorage, activation and effector functions. Since persistent "danger signals" triggered by the parasite and its antigens are required for the establishment of inflammation and ECM alterations, therapeutic interventions that control parasitism and selectively modulate cell migration improve ECM abnormalities, paving the way for the development of new therapeutic strategies improving the prognosis of $T$. cruzi-infected individuals.
\end{abstract}

Key words

- Trypanosoma cruzi

- Extracellular matrix

- Cell adhesion

- Cell migration

- Adhesion molecules

- Chemokines 


\section{Introduction}

As a common consequence of a combinatorial interplay between invader and host, inflammatory processes are established leading to invader control but frequently contributing to the establishment of chronic inflammatory disease. Inflammatory responses to tissue infection require cell migration, a widespread process that comprises cell-cell adhesion and cell-extracellular matrix (ECM) interaction and is orchestrated by cell adhesion molecules and integrin receptors, ECM components, matrix metalloproteinases and chemoattractant molecules. Migration is also a prerequisite for infectious agent spreading. Direct or bridge molecule-mediated interactions occur between invaders and host ECM and cells, being a crucial event for successful infection. We report here lines of evidence that these processes may occur during Trypanosoma cruzi infection that leads to a severe chronic diffuse and fibrosing myocarditis with the presence of rare parasites in $25-30 \%$ of infected patients.

\section{Trypanosoma cruzi-host cell interaction}

The parasite talks

The protozoan $T$. cruzi, the causative agent of Chagas' disease, invades mamma-

Figure 1. Trypanosoma cruzi antigen cruzipain (green) is detected associated with fibronectin fibers (red) in the myocardium of chronically ( 120 days postinfection) infected mice. The animals were infected with 100 trypomastigotes of the Colombian strain of $T$. cruzi. The arrows indicate the superposition of the labeling for fibronectin and cruzipain (yellow). Bar $=25 \mu \mathrm{m}$.

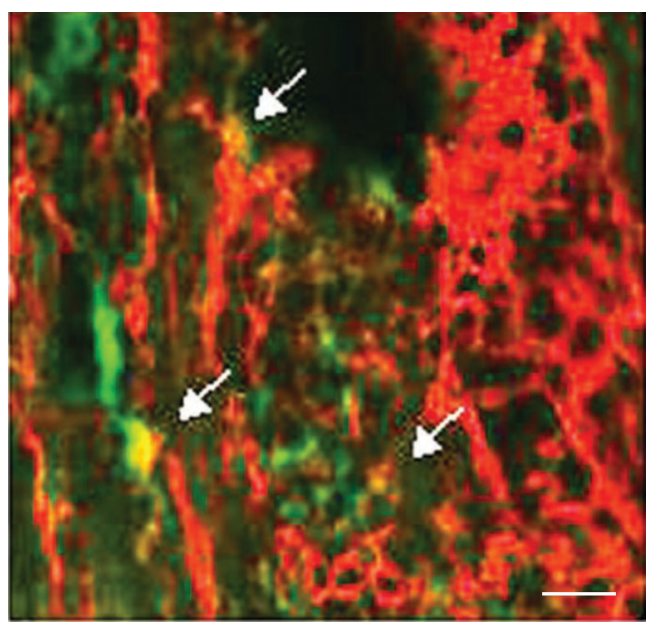

lian host cells as trypomastigote or amastigote forms to complete its biological cycle. The understanding of the molecular basis of the host cell invasion process by $T$. cruzi has been an almost centenary challenge in parasitology. Several lines of evidence demonstrate that the ECM glycoprotein fibronectin (FN) promotes adhesion and uptake of trypomastigotes by macrophages and fibroblasts $(1,2)$ and amastigotes by murine or human macrophages (3). Subsequent studies showed that $T$. cruzi trypomastigotes specifically recognize and bind to the RGDS amino acid sequence of FN that inhibits the infection of host cells (4). Moreover, the expression of parasite $\mathrm{FN}$ receptors characterized as a group of proteins ranging from 80 to $85 \mathrm{kDa}$, including a member of the trans-sialidase superfamily, is correlated with the parasite's ability to adhere to and invade host cells $(5,6)$.

It is commonly believed that as a prerequisite for host cell invasion, T. cruzi infective forms must cross basement membrane and ECM barriers. Recently, it has been reported that the binding of $T$. cruzi to laminin (LN), the major constituent of the basement membrane, is enhanced by galectin-3 (7). Also, a new class of T. cruzi molecules has been reported to play a crucial role facilitating parasite mobilization through the ECM. These T. cruzi ECM-binding proteins, including the $51 \mathrm{kDa}$ cysteine proteinase cruzipain, present enzymatic activity and mediate type I collagen and FN degradation $(8,9)$. In vivo, cruzipain also binds to the $\mathrm{FN}$ network present in the heart tissue of $T$. cruzi-infected mice (Figure 1), as previously demonstrated among the T. cruzi antigens released into the cardiac interstitial spaces of chagasic patients (10). Sites that are cryptic or hidden in the native ECM molecules may become activated or exposed upon disassembly or degradation of the ECM component structure by proteolytic enzymes that are released by interstitial parasites or, considering the whole event, secreted by tissue- 
invading leukocytes. As a biological consequence, the ECM breakdown products may facilitate invasion of target cells by the parasite. In fact, FN cleavage fragments were shown to provide a growth factor-like activity for the differentiation of trypomastigotes to amastigotes, a more efficient invasive form (11). In addition, in view of the ongoing $T$. cruzi-elicited myocarditis, the ECM degradation process may modulate ECM interactions with cytokines and chemokines involved in recruitment and/or activation of inflammatory cells (12), as discussed below.

The inflamed myocardium is exposed to parasite antigens either released into the cardiac interstitial spaces by extracellular parasites or from killed organisms. More recently, we have shown that proteins mainly ranging from 85 to $170 \mathrm{kDa}$ released by $T$. cruzi trypomastigotes within membrane vesicles adhered to membrane microvilli and were internalized by noninfected mammalian cells, including fibroblast and skeletal muscle cells. A cysteine proteinase, cruzipain, but not trans-sialidase, was detected among the cell-bound antigens. As a consequence of the adsorption of released antigens the sensitized cells became targets for anti- $T$. cruzi antibodies and presented increased expression of ECM components (13). Thus, the in vivo released $T$. cruzi antigens might be involved in the establishment of inflammation, sensitizing noninfected host cells, triggering an immune response against parasite antigens and modulating ECM expression that could mediate cell-cell or parasitehost cell interactions.

Recent studies have shown that an 80$\mathrm{kDa}$ serine protease located inside a vesicular compartment close to the flagellar pocket was found to hydrolyze FN and, more importantly, to be a potential target for a potent selective inhibitor that blocks $T$. cruzi entry into host cells $(8,14)$. Also, a new member of the $T$. cruzi $80-85-\mathrm{kDa}$ glycoprotein family was shown to bind to LN (15). Together with parasite-binding sites for host thrombospon- din, heparin sulfate and FN, this LN-binding site has been proposed to be a potential target for inhibition of invasion of host cells by $T$. cruzi by RNA aptamers $(16,17)$. Taken together, these data led to the concept that specific interactions between T. cruzi and host ECM components play a pivotal role in parasite dissemination, mediating basement membrane and ECM degradation as well as adhesion to and invasion of host cells. Moreover, these findings provide evidence that ECM-binding sites present on the T. cruzi surface are new potential therapeutic targets for inhibition of $T$. cruzi dissemination.

\section{The host answers}

The heart is the main organ affected during $T$. cruzi infection. The pathogenesis of tissue remodeling, particularly that which causes the unique apical aneurysm found in chagasic patients, remains unclear. Fibrosis is one of the most important features of the chronic chagasic cardiomyopathy with multifocal scarring frequently observed in the absence of significant inflammation or parasitized myocytes (18). More recently, it was shown that, compared with dilated cardiomyopathy, chronic chagasic myocarditis presents a distinctive pattern of ECM abnormalities (19). Increased expression of ECM components including FN, LN and types III and IV collagen, and remodeling of matrix components associated with the progression of inflammation have also been detected in the heart tissue of $T$. cruzi-infected mice (20). However, focal connective tissue damage with multiple areas devoid of ECM components was observed in inflamed atria of early acutely infected mice (21). It is possible that ECM degradation can precede or concurrently occur with enhanced fibrosis, and account for remodeling of cardiac tissue. In fact, alterations of the ECM may contribute to ventricular dysfunction and geometric shape changes observed in human and experimental T. cruzi-induced cardio- 
myopathy. These include loss of ECM components through degradation or mechanical destruction producing a thin-walled, dilated, and poorly contracting ventricle, even in the absence of significant myocyte injury (21).

Abnormal expression of ECM components seems to be a widespread event during T. cruzi infection. A progressive and intense increase in the intralobular network containing FN and type IV collagen was observed in the atrophic thymus of $T$. cruzi-infected mice (22). Further, a remarkable increase in the expression of $\mathrm{FN}$ and the basement membrane components LN and type IV collagen was also detected in other lymphoid (spleen and lymph nodes) and nonlymphoid tissues including skeletal muscle of $\mathrm{C} 3 \mathrm{H} / \mathrm{He}$ mice infected with the Colombian strain of $T$. cruzi (Figure 2). In skeletal muscle diffuse
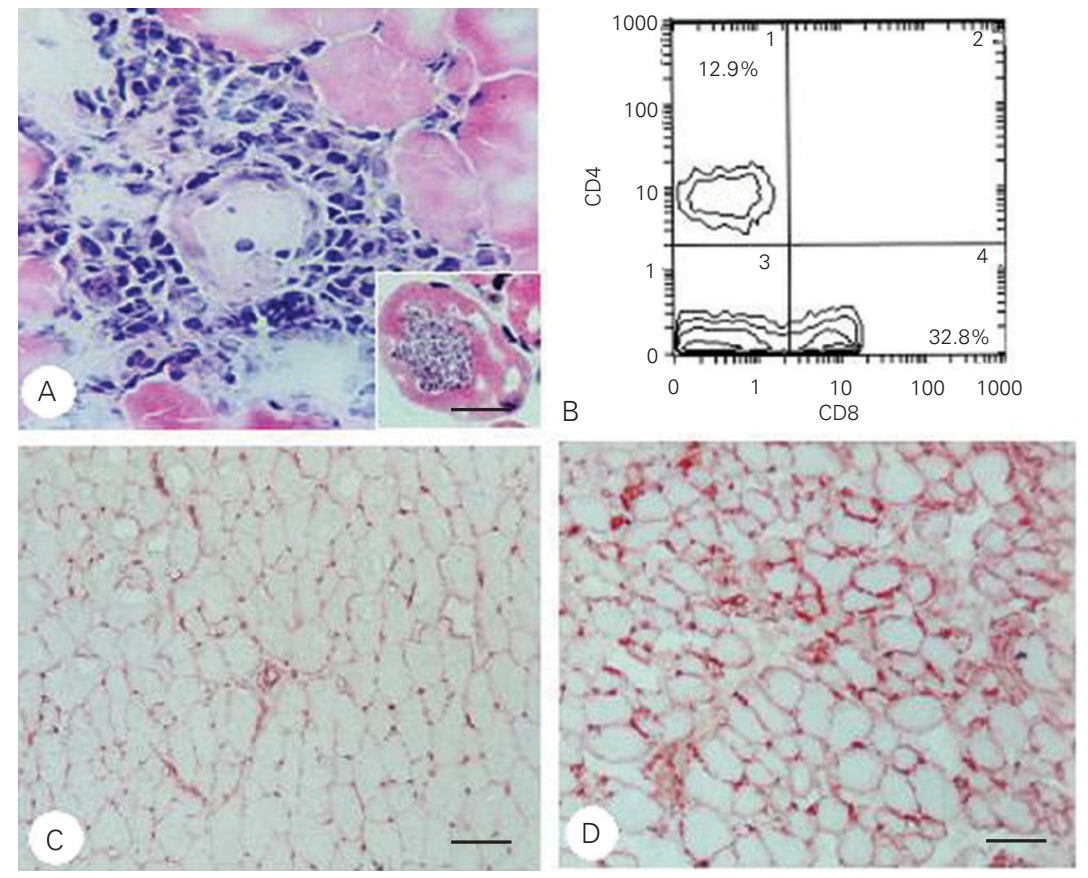

Figure 2. A, Conventional histopathological analysis (H\&E) of inflammatory infiltrates in the skeletal muscle of Trypanosoma cruzi-infected mice. Amastigote nest containing hundreds of parasites in the absence of inflammatory infiltrates at 35 days post-infection (inset). Bar $=25 \mu \mathrm{m}$. B. Flow cytometric analysis of mononuclear cells obtained from skeletal muscle of $T$. cruzi-infected mice shows the predominance of $C D 8^{+} T$ cells in chronically (120 days post-infection) T. cruzi-infected mice. Immunohistochemical analysis showed that compared with normal mice (C), chronically T. cruzi-infected mice (D) present increased expression of type IV collagen in the basal lamina of skeletal muscle cells. Bars $=100 \mu \mathrm{m}$. inflammation composed mainly of mononuclear cells is initially detected in the early acute phase. It was paralleled by ECM abnormalities that are observed in areas with inflammatory infiltrates and areas not affected by myositis, and related or not to the presence of parasite pseudocysts and antigens. Interestingly, the phenotypic analysis of mononuclear cells isolated enzymatically (23) from skeletal muscle showed that the inflammatory infiltrates were composed mainly of $\mathrm{CD}^{+} \mathrm{T}$ cells (Figure 2). This finding is particularly relevant considering the prevalence of this $\mathrm{T}$ cell subset in the cardiac tissue of chagasic patients presenting severe myocarditis $(24,25)$ and in the inflamed heart of $\mathrm{C} 3 \mathrm{H} / \mathrm{He}$ mice chronically infected with the Colombian strain (23). In this experimental model, CD8-mediated myocarditis is established during the early acute infection (Figure 3 ) and persists during the chronic phase (23). Also, CD8-mediated meningoencephalitis restricted to the acute phase is observed in this animal model (26). The findings showing the establishment of inflammatory infiltrates composed mainly of $\mathrm{CD}^{+} \mathrm{T}$ cells in several target tissues during the early acute phase indicate the importance of $\mathrm{CD} 8{ }^{+} \mathrm{T}$ cells in the resistance to T. cruzi (27). Moreover, these data support the idea that during $T$. cruzi infection the preferential migration of $\mathrm{CD} 8^{+} \mathrm{T}$ cells towards target tissues results from the differential activation profile of this cell population, being coordinated by parasite-driven chemoattractant molecules expressed in target tissues (23 and Roffê E, Silva AA, Santiago HC, Gazzinelli RT and LannesVieira J, unpublished data).

The intense increase in the expression of the cardiac ECM proteins FN, type IV collagen and LN exists as an interstitial framework surrounding and interconnecting infected and noninfected skeletal muscle (Figure 2) or cardiac myocytes (Figures 4 and 5) of Colombian strain-infected $\mathrm{C} 3 \mathrm{H} / \mathrm{He}$ mice. Laminin expression was significantly in- 
creased in the cardiac tissue of $T$. cruziinfected mice, particularly in the basal lamina of cardiomyocytes, and absent in areas of inflammatory infiltrates (Figure 4). In addition, the $\beta 1$ integrin $L N$ receptor VLA- 6 was not immunohistochemically detected on the surface of infiltrating cells, although rare interstitial cells were $\alpha 6^{+}$(Figure 4). Similarly, in the inflammation of the central nervous system of acutely $T$. cruzi-infected $\mathrm{C} 3 \mathrm{H} /$ $\mathrm{He}$ mice, $\mathrm{LN}$ expression restricted to the basement membrane of blood vessels was enhanced, whereas VLA-6 was absent on infiltrating perivascular cells (28). Regarding the functional role of LN and VLA-6 in the physiopathogenesis of myocarditis during $T$. cruzi infection, it was previously shown that antibodies recognizing $\mathrm{LN}$ and its receptor VLA- 6 are able to block the migration of locally injected splenic $\mathrm{CD}^{+}{ }^{+} \mathrm{T}$ cells obtained from chronically $T$. cruzi-infected mice to cardiac tissue grafted in the ear of normal mice (29). This finding suggests the participation of LN/VLA-6 interactions in cell migration towards the heart tissue of T. cruziinfected mice. Our findings do not rule out this possibility; however, it is possible that after transmigration through the endothelial layer, inflammatory cells may lose or downmodulate the expression of VLA-6 (30).

Interestingly, we have shown that the FN mesh present in the inflamed heart of chronically $T$. cruzi-infected mice involves VLA- $4^{+}$ macrophages, and activated VLA- $4^{+}$LFA- $1^{+}$ $\mathrm{CD}^{+}$and $\mathrm{CD}^{+}{ }^{+} \mathrm{T}$ cells (23). Moreover, mononuclear cells expressing VLA-4 and CD44 were detected immunohistochemically in the myocardium of chronic chagasic patients (31), suggesting that these inflammatory cells are activated and able to interact with ECM components. When $\mathrm{C} 3 \mathrm{H} / \mathrm{He}$ mice were inoculated with the Colombian strain during the early acute phase (14-28 days post-infection), most of the infiltrating inflammatory cells, including both $\mathrm{CD}^{+}$and CD8 ${ }^{+}$Tlymphocytes, were VLA- $4^{+}$, whereas only a minor population of the mononuclear cells inside the inflamed cardiac tissue expressed VLA-5 (Figure 6). Furthermore, we have shown that the predominance of $\mathrm{CD}^{+}$ $\mathrm{T}$ cells in $T$. cruzi-infected heart observed during chronic infection (23) is also achieved during the early acute phase, paralleling the ECM alterations.

The role of FN and its receptors in the physiopathogenesis of the chronic T. cruzielicited myocarditis is unclear. The $\beta 1$ integrin FN receptors on macrophages may contribute to $T$. cruzi dissemination. In fact, it has been reported that $T$. cruzi uptake and subsequent replication inside macrophages

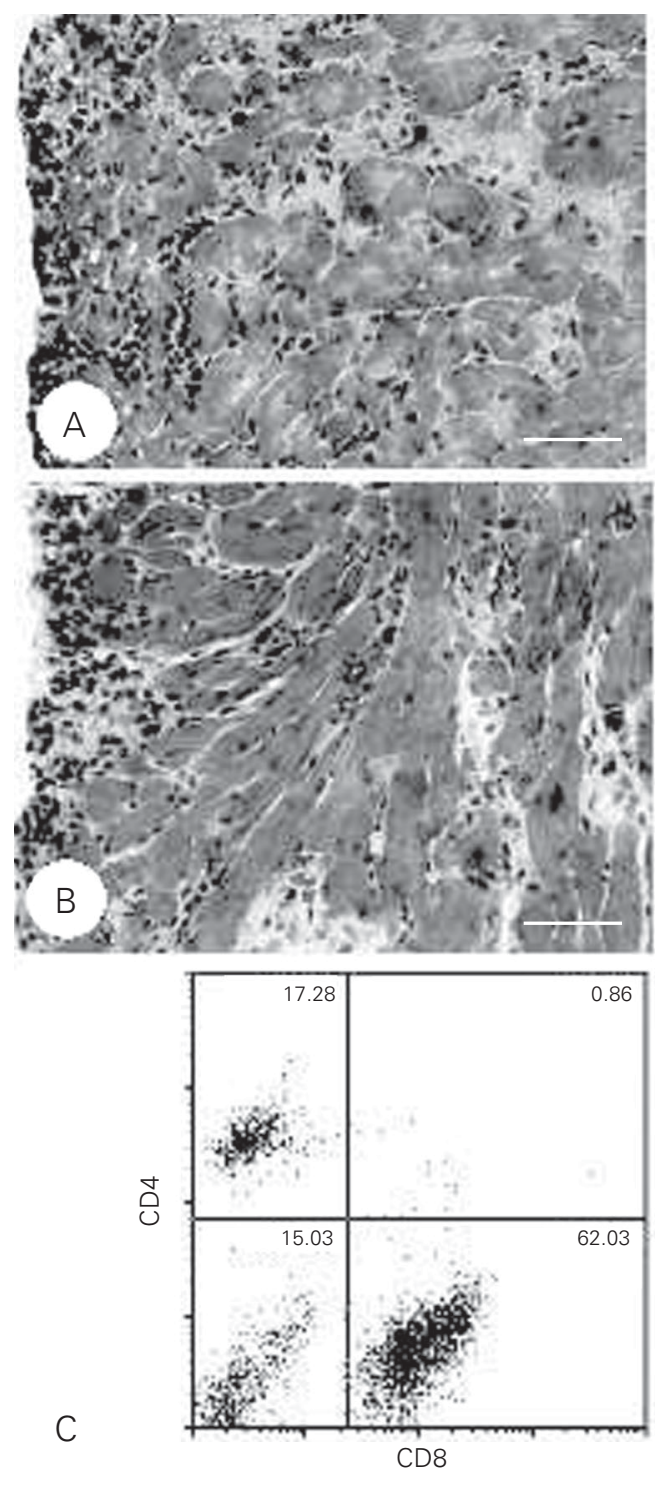

Figure 3. Conventional histopathological analysis (H\&E) of inflammatory infiltrates in the cardiac tissue of $\mathrm{C} 3 \mathrm{H} / \mathrm{He}$ mice during the acute $(A)$ and chronic $(B)$ phases. Bars $=100 \mu \mathrm{m}$. Flow cytometric analysis of mononuclear cells obtained from cardiac tissue of acutely (28 days post-infection) Trypanosoma cruzi-infected $\mathrm{C} 3 \mathrm{H} / \mathrm{He}$ mice shows the predominance of $\mathrm{CD}^{+} \mathrm{T}$ cells $(\mathrm{C})$. 
Figure 4. Confocal analysis of laminin (LN) expression in the cardiac tissue of normal (A) and acutely (B) Trypanosoma cruziinfected $\mathrm{C} 3 \mathrm{H} / \mathrm{He}$ mice. $\mathrm{LN}$ is not detected surrounding the inflammatory cells (red). Immunohistochemical analysis showed that the increased expression of LN is restricted to the basal lamina of myocytes and basement membrane of blood vessels (C). The $\beta 1$ integrin $L N$ receptor VLA-6 is absent on mononuclear cells infiltrating the cardiac tissue of $T$. cruzi-infected mice (D). Bars $=25 \mu \mathrm{m}$.
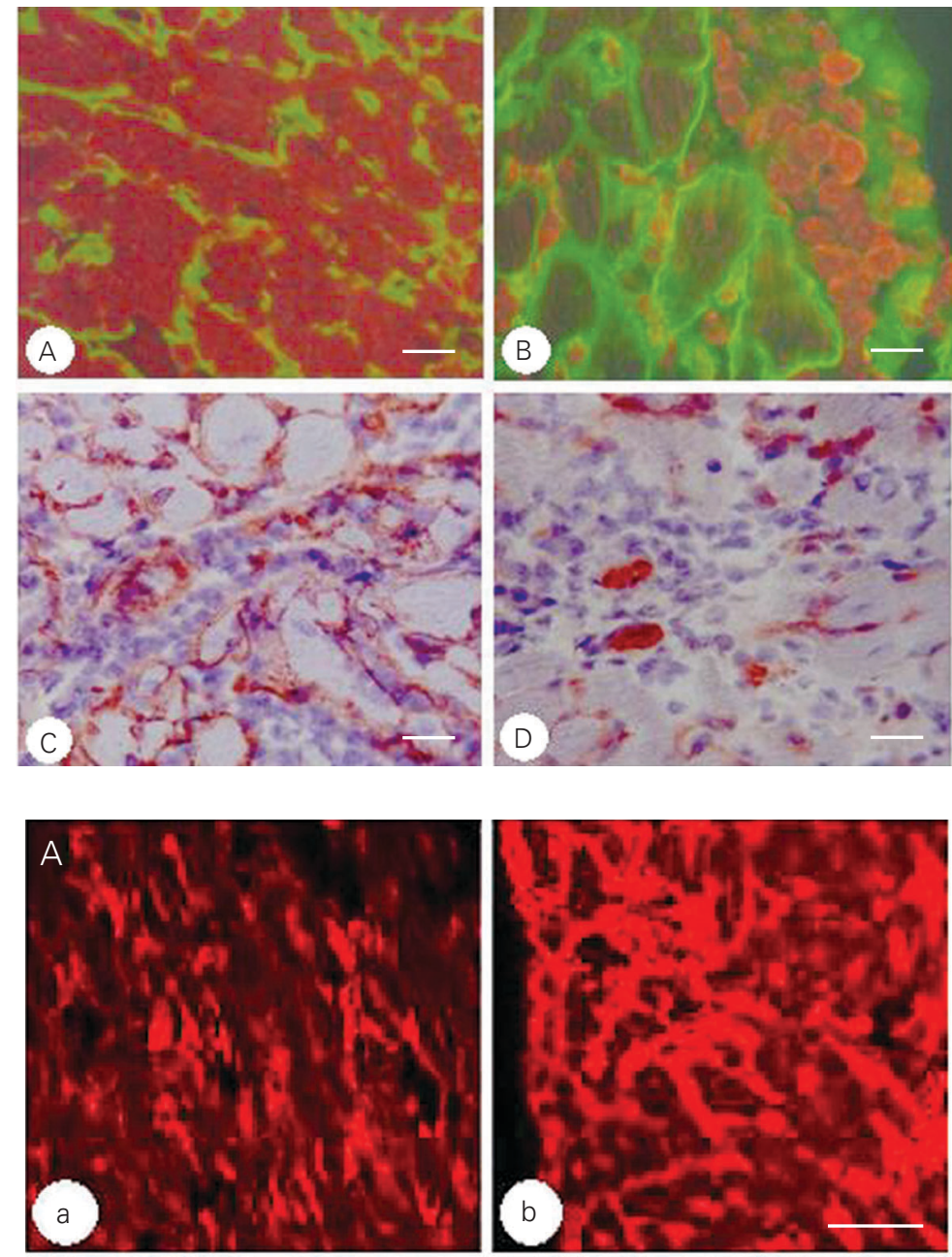

Figure 5. Panel A, Confocal analysis of fibronectin (FN) expression in the cardiac tissue of normal (a) and acutely Trypanosoma cruzi-infected (b) $\mathrm{C} 3 \mathrm{H} / \mathrm{He}$ mice. Panel $B$ depicts an immunohistochemical analysis of the cardiac tissue of $T$. cruzi-infected mice showing that a fine FN network surrounds noninfected and infected (arrow) cardiomyocytes (a). This FN mesh also surrounds $\alpha 4^{+}$mononuclear cells (b) that are $\mathrm{CD}^{+}$(c) and mostly $\mathrm{CD}^{+}$(d) lymphocytes. Serial section of $5 \mu \mathrm{m}$. Bars $=25 \mu \mathrm{m}$
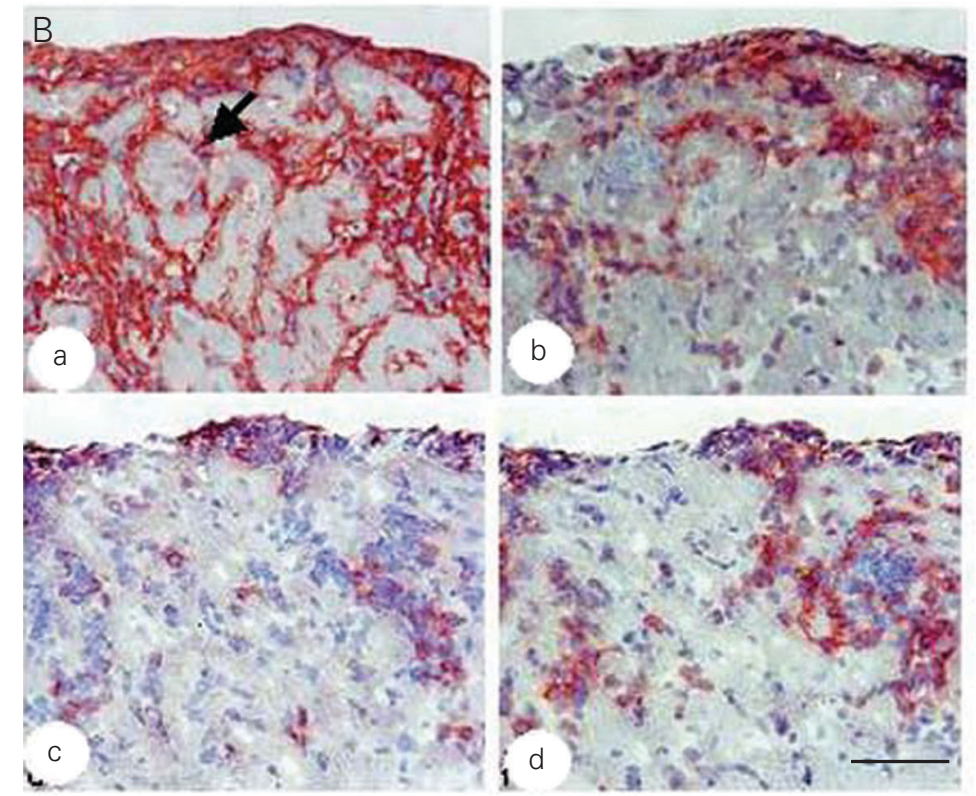
A
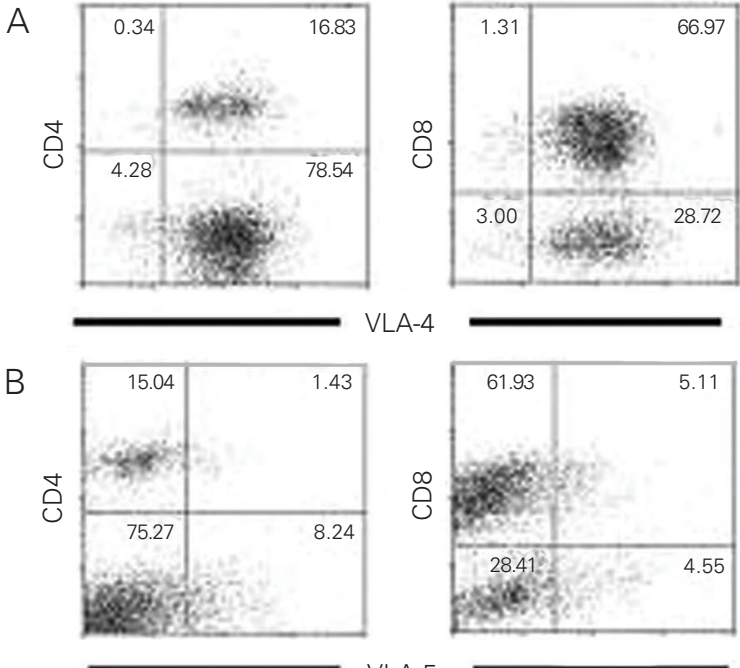

VLA-5
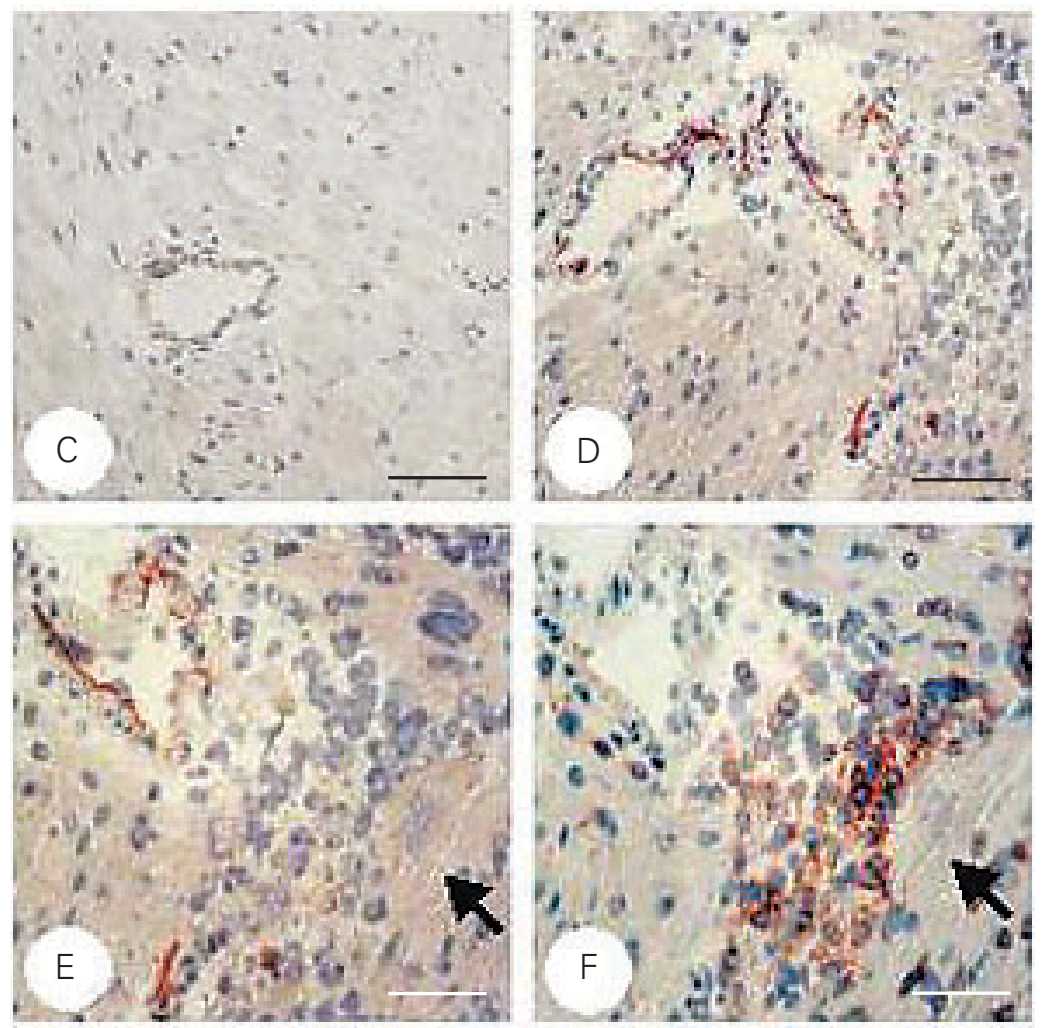

Figure 6. Flow cytometric analysis of mononuclear cells obtained from cardiac tissue of acutely Trypanosoma cruzi-infected $\mathrm{C} 3 \mathrm{H} / \mathrm{He}$ mice shows that most of the $\mathrm{CD}^{+}$and $\mathrm{CD}^{+} \mathrm{T}$ cells are $\mathrm{VLA}-4^{+}(\mathrm{A})$, whereas a small fraction of $\mathrm{CD} 4^{+}$and $\mathrm{CD} 8^{+}$lymphocytes express VLA-5 (B). Immunohistochemical analysis showed that compared with normal mice (C), acutely (28 days post-infection) T. cruzi-infected mice (D) present increased expression of the adhesion molecule VCAM-1 on endothelial cells of cardiac tissue. Bars $=50 \mu \mathrm{m}$. The perivascular space of VCAM-1+ blood vessels (E) was filled with $\alpha 4^{+}$ mononuclear cells (F). The arrow indicates the presence of an amastigote nest inside a cardiomyocyte. Bars $=25 \mu \mathrm{m}$. 
is inhibited by treatment of mammalian cells with anti- $\beta 1$ integrin antibodies, but not with anti-32 integrin. Also, partial inhibition of parasite uptake by anti-VLA-4 and antiVLA-5 antibodies suggested that several members of the $\beta 1$ integrin family, in addition to the FN receptors VLA-4 and VLA-5, are involved in $T$. cruzi binding to and entry into macrophages (32).

A fine network of FN involving VLA-4+ mononuclear inflammatory cells and infected or noninfected neurons and glial cells (astrocytes and microglia) was shown to be present in the central nervous system of Colombian strain-infected $\mathrm{C} 3 \mathrm{H} / \mathrm{He}$ mice during acute infection; however, this inflammation is self-resolving and chronic alterations are not present at this site $(26,28)$, whereas a progressive myocarditis paralleled by ECM abnormalities is observed in these mice (23). The distribution of variant forms of $\mathrm{FN}$ in anatomic sites in vivo remains unknown but it has been suggested that VLA-4-dependent co-stimulation of $\mathrm{T}$ cells may be restricted to certain critical anatomic sites in vivo (33). It is reasonable to propose that interactions of T cells with the fine FN filamentous network present in the inflamed myocardium via VLA-4 molecules may provide an anchor for invading cells and not only function as a pathway in the $\mathrm{T}$ cell migration processes but may also influence antigen-specific $\mathrm{T}$ cell recognition, proliferation, survival and effector activity (34). In addition, FN and other ECM components may also act as chemoattractants for additional invading cells or provide a substrate for the anchoring and stabilization of chemoattractant molecules $(35,36)$, contributing to the perpetuation of inflammation in this tissue. Further as discussed above, T. cruzi antigens present proteolytic activity resulting in ECM breakdown products that are themselves potentially immunomodulatory and could contribute to the maintenance of chronic inflammation. Indeed, it has been shown that damaged ECM activates macrophages to secrete IL-12 and chemokines $(37,38)$, cytokines present in the inflamed heart of chronic chagasic patients $(24,25)$, and in acute and chronic experimentally $T$. cruzi-infected mice $(23,39$, 40). These cytokines play a central role by controlling tissue parasitism during $T$. cruzi infection but are also involved in the maintenance of chronic myocarditis (41-44).

With respect to putative sources of ECM components in $T$. cruzi-infected inflamed target tissues, the inflammatory mononuclear cells may contribute to $\mathrm{FN}$ production as activated macrophages and $\mathrm{T}$ lymphocytes produce this glycoprotein $(45,46)$. However, the possibility that myocytes and other cell types present in these tissues could also contribute to ECM production cannot be ruled out. In fact, our results show an increased expression of FN and LN by infected and noninfected neurons and glial cells (astrocytes and microglia) (28) of acutely $T$. cruziinfected mice, and FN, type IV collagen and LN in the basal lamina of infected and noninfected cardiac (23) and skeletal muscle cells of acutely and chronically infected mice. Also, in vitro studies have shown that several other cell types when infected with $T$. cruzi present abnormal quantitative and qualitative production of ECM components (13, 47). In this respect, in addition to a remarkable increase in ECM production by T. cruziinfected endothelial cells, the heparan sulfate proteoglycan isolated from this ECM differed from the heparan sulfate proteoglycan obtained from the ECM of noninfected cells by virtue of an eight- to ten-fold increase in sulfation besides other biochemical properties. Also, this modified heparan sulfate proteoglycan binds more efficiently to acidic fibroblast growth factor. Moreover, the ECM produced by infected endothelial cells can direct the synthetic patterns of noninfected cells in a manner uniquely observed in infected endothelial cells, suggesting a plausible pathway by which infection of only a few cells can ultimately result in the coordinate responses of neighboring noninfected 
cells (47). Since that gene expression is regulated by the surrounding ECM (38), these results could partially explain the drastic alterations of ECM expression as well as other products observed during chronic chagasic myocardiopathy in the presence of only few parasites.

The modulators of ECM and the mechanisms leading to increased ECM expression in the inflamed myocardium during T. cruzi infection are not known. In view of the data described above, the ECM produced by $T$. cruzi-infected cells could itself modulate the ECM synthesized by other cells $(38,47)$. Further, our findings showing that adsorption of T. cruzi-released antigens to noninfected cells induced an increase in ECM production by sensitized monkey epithelial cells and murine fibroblast and skeletal muscle cells suggest that parasite antigens could directly contribute to the establishment of ECM abnormalities and tissue remodeling during acute and chronic Chagas' disease (13). It should also be considered that soluble factors such as cytokines, chemokines and growth factors produced by $T$. cruzi-infected cells or parasite antigen-sensitized noninfected cells may contribute to the overall alterations of ECM in target tissues during $T$. cruzi infection. In this context, a fibroblast-stimulating factor was identified in cell-free conditioned media from $T$. cruzi-infected cultures of fibroblasts, vascular smooth muscle cells and myocytes, suggesting that the infection of mesenchymal cells by $T$. cruzi could stimulate the production of modified ECM and thereby initiate the myocardial fibrosis typical of Chagas' disease (48). More recently it was shown that $T$. cruzi-infected macrophages and cardiomyocytes and antigen-stimulated macrophages produce chemokines $(40,42,49)$. Interestingly, a FN mesh surrounding IFN- $\gamma$-producing inflammatory cells and ECM-associated cytokine was frequently detected in the heart tissue of $T$. cruzi-infected mice (Roffê E and LannesVieira J, unpublished data). Thus, it is pos- sible that interactions of cytokines and chemokines with FN and other ECM components or enzymatically modified ECM may affect the distribution and pleiotropic activities of these molecules in inflamed tissues, where the cytokines may act as proadhesive molecules, strengthening cell binding to the ECM, thereby promoting cell activation $(36,50)$. Hence, presentation of cytokines and chemokines by ECM molecules in the inflamed tissue of $T$. cruzi-infected mice could contribute to cell recruitment, migration and activation leading to the maintenance of inflammatory foci in a particular microenvironment as well as ECM overproduction by mesenchymal or invading inflammatory cells.

It is also possible that products of the inflammatory cells (such as IFN- $\gamma$, TNF- $\alpha$ and chemokines) detected in the heart tissue of chagasic patients $(24,25)$ and heart and central nervous system of animals experimentally infected with $T$. cruzi $(23,39,40$ and Roffê E, Silva AA, Santiago HC, Gazzinelli RT and Lannes-Vieira J, unpublished data), demonstrated to modulate ECM expression $(38,46,51,52)$, could contribute to the increase in ECM expression in several tissues. Furthermore, systemic hormones such as glucocorticoids (53) and cytokines such as IFN- $\gamma(54)$ and TNF- $\alpha$ (55) detected in elevated levels in the serum of T. cruzi-infected mice may also induce alterations in ECM expression in the target tissues. Further, local and systemically produced proinflammatory cytokines may modulate the expression of adhesion molecules such as ICAM-1 and VCAM-1 on the endothelial cells $(56,57)$ and hence promote cellular infiltration of lymphocytes and other effector cells into the inflamed tissues. In fact, ICAM- $1^{+}$and VCAM- $1^{+}$blood vessels associated with $\mathrm{CD}^{+}{ }^{+}$-infiltrating $\mathrm{T}$ cells were detected in the cardiac tissue of chagasic patients with severe cardiomyopathy (58). More recently, we have shown that during experimental chronic chagasic infection there 
is a remarkable increase in the expression of VCAM-1 on the endothelial cells of heart blood vessels (23). As shown in Figure 6, this up-regulated VCAM-1 expression was observed initially during the early acute phase and paralleled the presence of perivascular VLA-4 ${ }^{+}$-activated mononuclear cells. In addition, ICAM-1 expression that was low on endothelial cells of cardiac tissue of noninfected animals was upregulated in T. cruziinfected mice. Further, $\mathrm{LFA}^{-1}{ }^{+}$and ICAM- ${ }^{+}$ cells were detected on invading inflammatory cells (Marino APMP, Azevedo MIP and Lannes-Vieira J, unpublished data). Using murine models susceptible and resistant to the development of acute $T$. cruzi-elicited meningoencephalitis, we have demonstrated that VLA-4/VCAM-1 interactions are crucial for the establishment of inflammation in the central nervous system during chagasic infection (Roffê E, Silva AA, Marino APMP, dos Santos PVA and Lannes-Vieira J, unpublished data). Interestingly, we have reported that the distribution of LFA- $1^{+} \mathrm{VLA}-4^{+}-$ activated $\mathrm{CD}^{+}$and $\mathrm{CD} 8^{+} \mathrm{T}$ cell populations in the myocardium mirrors the frequency of cells expressing the CD62L Low LFA- $1^{\text {High }}$ VLA-4 ${ }^{\text {High }}$ activation phenotype among $\mathrm{CD} 4^{+}$ and $\mathrm{CD} 8^{+}$peripheral blood $\mathrm{T}$ cells (23), reinforcing the importance of adhesion molecules for the establishment of inflammation in target tissues during $T$. cruzi infection. In fact, this was recently confirmed using IFN- $\gamma$ and IL-12-immunodeficient mice that present a decreased myocarditis during the early acute infection (15 days post-infection) in parallel to a diminished expression of VCAM-1 and ICAM-1 on endothelial cells when compared with wild-type C57BL/6 mice. Moreover, the heart tissue of T. cruziinfected ICAM-1-deficient mice was devoid of significant inflammation and the animals succumbed promptly to infection (Michailowsky V, Celes MRN, Marino APMP, Rossi M, Gazzinelli RT, Lannes-Vieira J and Silva JS, unpublished data). The findings discussed above provide evidence that profound alter- ations in the expression of ECM, cytokines, and adhesion and chemoattractant molecules are observed in several target tissues as a consequence of $T$. cruzi infection. All of these molecules may play a beneficial role leading to activation, recruitment and migration of cells involved in the control of the parasite but may also contribute to the establishment of adverse consequences such as chronic inflammation and organ dysfunction.

\section{Interfering with the Trypanosoma cruzi-host interplay}

The pathogenesis of $T$. cruzi-elicited myocarditis remains unknown, but it is probably multifactorial as discussed above. Regardless of the mechanisms, ECM alterations may result from and/or contribute to the chronic cardiac inflammation. Since the parasite is apparently required for the continuous supply of "danger signals" that result in damage to cardiac tissue (59), the elimination of the parasite may cause clearance or partial regression of inflammatory lesions in target tissues. It has been shown that specific chemotherapy leads to reversibility of cardiac fibrosis in mice chronically infected with $T$. cruzi. Interestingly, the improvement in ECM abnormalities in benznidazole-treated mice correlated with a drastic reduction in inflammation (60). Thus, we may propose that an immunomodulatory treatment that selectively blocks or diminishes the entry of deleterious inflammatory cells into the cardiac tissue of T. cruzi-infected mice could also be beneficial. Our recent findings showing a predominance of CC chemokines, especially RANTES (regulated on activation normal T cell expressed and secreted) and MIP- $1 \alpha$ (macrophage inflammatory protein- $1 \alpha$ ), and cells bearing CC receptors, mainly CCR5, in the cardiac tissue of $T$. cruzi-infected mice associated with preferential expression of CCR5 on peripheral blood CD8 ${ }^{+} \mathrm{T}$ cells $(23$ and Marino APMP, Silva AA, dos Santos 
PVA, Pinto LMO, Gazzinelli RT, Teixeira MM and Lannes-Vieira J, unpublished data) led us to propose that $\mathrm{CC}$ chemokines and their receptors are involved in differential cell migration and pathogenesis of T. cruzielicited CD8-mediated myocarditis. Importantly, the treatment of acutely $T$. cruzi-infected mice with methionylated RANTES, an antagonist of CC chemokines, significantly decreased the inflammatory infiltrates due to CD4 and CD8 T cells, but decreased or did not interfere with heart parasitism depending on the therapeutic scheme used. Furthermore, these effects were accompanied by a decrease in ECM expression (Marino APMP, Silva AA, dos Santos PVA, Pinto LMO, Gazzinelli RT, Teixeira MM and Lannes-Vieira J, unpublished data), re- inforcing the idea that fibrosis is related to the presence of $T$. cruzi and inflammation in the cardiac tissue during chagasic infection. Thus, we propose that a therapeutic intervention ultimately leading to modulation of ECM expression could contribute to improving the prognosis of $T$. cruzi-infected individuals.

\section{Acknowledgments}

The authors are grateful to Patrícia A. Moreno Martinez, Department of Pathology, Oswaldo Cruz Institute, Fiocruz, for Confocal acquisition and Heloisa Diniz and Rodrigo Cunha Mexas, Laboratory of Image, Oswaldo Cruz Institute, Fiocruz, for preparing the figures.

\section{References}

1. Wirth JJ \& Kierszenbaum F (1984). Fibronectin enhances macrophage association with invasive forms of Trypanosoma cruzi. Journal of Immunology, 133: 460-464.

2. Ouaissi MA, Cornette J \& Capron A (1985). Trypanosoma cruzi: modulation of parasite-cell interaction by plasma fibronectin. European Journal of Immunology, 15: 1096-1101.

3. Noisin EL \& Villalta F (1989). Fibronectin increases Trypanosoma cruzi amastigote binding to and uptake by murine macrophages and human monocytes. Infection and Immunity, 57: 1030-1034.

4. Ouaissi MA, Cornette J, Afchain D, Capron A, Gras-Masse H \& Tartar A (1986). Trypanosoma cruzi infection inhibited by peptides modeled from a fibronectin cell attachment domain. Science, 234: 603-607.

5. Velge P, Ouaissi MA, Cornette J, Afchain D \& Capron A (1988). Identification and isolation of Trypanosoma cruzi trypomastigote collagen-binding proteins: possible role in cell-parasite interaction. Parasitology, 97: 255-268.

6. Low HP \& Tarleton RL (1997). Molecular cloning of the gene encoding the $83 \mathrm{kDa}$ amastigote surface protein and its identification as a member of the Trypanosoma cruzi sialidase superfamily. Molecular and Biochemical Parasitology, 88: 137-149.

7. Moody TN, Ochieng J \& Villalta F (2000). Novel mechanism that Trypanosoma cruzi uses to adhere to the extracellular matrix mediated by human galectin-3. FEBS Letters, 470: 305-308.

8. Santana JM, Grellier P, Schrevel J \& Teixeira AR (1997). A Trypanosoma cruzi-secreted $80 \mathrm{kDa}$ proteinase with specificity for human collagen types I and IV. Biochemical Journal, 325: 129-137.

9. Scharfstein J \& Morrot A (1999). A role for extracellular amastigotes in the immunopathology of Chagas disease. Memórias do Instituto Oswaldo Cruz, 94 (Suppl 1): 51-63.

10. Morrot A, Strickland DK, Higuchi Mde L, Reis M, Pedrosa R \& Scharfstein J (1997). Human T cell responses against the major cysteine proteinase (cruzipain) of Trypanosoma cruzi: role of the multifunctional alpha 2-macroglobulin receptor in antigen presentation by monocytes. International Immunology, 9: 825-834.

11. Ouaissi A, Cornette J, Schoneck R, Plumas-Marty B, Taibi A, Loyens M \& Capron A (1992). Fibronectin cleavage fragments provide a growth factor-like activity for the differentiation of Trypanosoma cruzi trypomastigotes to amastigotes. European Journal of Cell Biology, 59: 68-79.

12. Gilat D, Cahalon L, Hershkoviz R \& Lider O (1996). Interplay of T cells and cytokines in the context of enzymatically modified extracellular matrix. Immunology Today, 17: 16-20.

13. Pinho RT, Vannier-Santos MA, Alves CR, Marino AP, Castello Branco LR \& Lannes-Vieira J (2002). Effect of Trypanosoma cruzi released antigens binding to noninfected cells on anti-parasite antibody recognition and expression of extracellular matrix components. Acta Tropica, 83: 103-115.

14. Grellier P, Vendeville S, Joyeau R et al. (2001). Trypanosoma cruzi prolyl oligopeptidase Tc80 is involved in nonphagocytic mammalian cell invasion by trypomastigotes. Journal of Biological Chemistry, 276: 47078-47086.

15. Giordano R, Fouts DL, Tewari D, Colli W, Manning JE \& Alves MJ (1999). Cloning of a surface membrane glycoprotein specific for the infective form of Trypanosoma cruzi having adhesive properties to laminin. Journal of Biological Chemistry, 274: 3461-3468.

16. Ulrich H, Alves MJM \& Colli W (2001). RNA and DNA aptamers as potential tools to prevent cell adhesion in disease. Brazilian Journal of Medical and Biological Research, 34: 295-300.

17. Ulrich H, Magdesian MH, Alves MJ \& Colli W (2002). In vitro selection of RNA aptamers that bind to cell adhesion receptors of Trypanosoma cruzi and inhibit cell invasion. Journal of Biological Chemistry, 277: 20756-20762

18. Andrade ZA, Andrade SG, Oliveira GB \& Alonso DR (1978). Histopathology of the conducting tissue of the heart in Chagas' myocarditis. American Heart Journal, 95: 316-324. 
19. Higuchi ML, Fukasawa S, De Brito T, Parzianello LC, Bellotti G \& Ramires JA (1999). Different microcirculatory and interstitial matrix patterns in idiopathic dilated cardiomyopathy and Chagas' disease: a three dimensional confocal microscopy study. Heart, 82: 279-285.

20. Andrade SG, Grimaud JA \& Stocker-Guerret S (1989). Sequential changes of the connective matrix components of the myocardium (fibronectin and laminin) and evolution of the cardiac fibrosis in mice infected with Trypanosoma cruzi. American Journal of Tropical Medicine and Hygiene, 40: 252-260.

21. Factor SM, Tanowitz H, Wittner M \& Ventura MC (1993). Interstitial connective tissue matrix alterations in acute murine Chagas' disease. Clinical Immunology and Immunopathology, 68: 147-152.

22. Savino W, Leite-de-Moraes MC, Hontebeyrie-Joskowicz M \& Dardenne M (1989). Studies on the thymus in Chagas' disease. I. Changes in the thymic microenvironment in mice acutely infected with Trypanosoma cruzi. European Journal of Immunology, 19: 17271733.

23. dos Santos PVA, Roffê E, Santiago HC, Torres RA, Marino APMP, Paiva CN, Silva AA, Gazzinelli RT \& Lannes-Vieira J (2001). Prevalence of CD8+ $\alpha \beta$ T cells in Trypanosoma cruzi-elicited myocarditis is associated with acquisition of CD62LLowLFA-1 HighVLA-4High activation phenotype and expression of IFN- $\gamma$-inducible adhesion and chemoattractant molecules. Microbes and Infection, 3: 971-984.

24. D'Ávila Reis D, Jones E, Tostes Jr S, Lopes ER, Gazzinelli G, Colley DG \& McCurley TL (1993). Characterization of inflammatory infiltrates in chronic chagasic myocardial lesions: presence of tumor necrosis factor- $\alpha^{+}$cells and dominance of granzyme $\mathrm{A}^{+}, \mathrm{CD} 8^{+}$lymphocytes. American Journal of Tropical Medicine and Hygiene, 48: 637-644

25. Reis MM, Higuchi ML, Benvenuti LA, Aiello VD, Gutierrez PS, Bellotti $G$ \& Pileggi $F$ (1997). An in situ quantitative immunohistochemical study of cytokines and IL-2 $\mathrm{R}^{+}$in chronic human chagasic myocarditis: correlation with the presence of myocardial Trypanosoma cruzi antigens. Clinical Immunology and Immunopathology, 83: 165-172.

26. Silva AA, Roffê E, Marino APMP, Santos PVA, Quirico-Santos T, Paiva CN \& Lannes-Vieira J (1999). Chagas' disease encephalitis: intense $\mathrm{CD}^{+}$lymphocytic infiltrate is restricted to the acute phase, but is not related to the presence of Trypanosoma cruzi antigens. Clinical Immunology, 92: 56-66.

27. Tarleton RL, Sun J, Zhang L \& Postan M (1994). Depletion of T-cell subpopulations results in exacerbation of myocarditis and parasitism in experimental Chagas' disease. Infection and Immunity, 62: 18201829.

28. Silva AA, Roffê E \& Lannes-Vieira J (1999). Expression of extracellular matrix components and their receptors in the central nervous system during experimental Trypanosoma cruzi infection. Brazilian Journal of Medical and Biological Research, 32: 593-600.

29. Silva-Barbosa SD, Cotta-de-Almeida V, Riederer I, De Meis J, Dardenne M, Bonomo A \& Savino W (1997). Involvement of laminin and its receptor in abrogation of heart graft rejection by autoreactive T cells from Trypanosoma cruzi-infected mice. Journal of Immunology, 159: 997-1003.

30. Romanic AM, Graesser D, Baron JL, Visintin I, Janeway Jr CA \& Madri JA (1997). T cell adhesion to endothelial cells and extracellular matrix is modulated upon transendothelial cell migration. Laboratory Investigation, 76: 11-23.

31. D'Ávila Reis D, Jones EM, Tostes Jr S, Lopes ER, Chapadeiro E, Gazzinelli G, Colley DG \& McCurley TL (1993). Expression of major histocompatibility complex antigens and adhesion molecules in hearts of patients with chronic Chagas' disease. American Journal of Tropical Medicine and Hygiene, 49: 192-200.
32. Fernandez MA, Munoz-Fernandez MA \& Fresno M (1993). Involvement of beta 1 integrins in the binding and entry of Trypanosoma cruzi into human macrophages. European Journal of Immunology, 23: 552-557.

33. Shimizu Y, Van Seventer GA, Horgan KJ \& Shaw S (1990). Regulated expression and binding of three VLA (beta 1) integrin receptors on T cells. Nature, 345: 250-253.

34. Rose DM, Han J \& Ginsberg MH (2002). $\alpha 4$ integrins and the immune response. Immunological Reviews, 186: 118-124.

35. Vaday GG \& Lider O (2000). Extracellular matrix moieties, cytokines, and enzymes: dynamic effects on immune cell behavior and inflammation. Journal of Leukocyte Biology, 67: 149-159.

36. Vaday GG, Franitza S, Schor H, Hecht I, Brill A, Cahalon L, Hershkoviz R \& Lider O (2001). Combinatorial signals by inflammatory cytokines and chemokines mediate leukocyte interactions with extracellular matrix. Journal of Leukocyte Biology, 69: 885-892.

37. Hodge-Dufour J, Noble PW, Horton MR, Bao C, Wysoka M, Burdick MD, Strieter RM, Trinchieri G \& Pure E (1997). Induction of IL-12 and chemokines by hyaluronan requires adhesion-dependent priming of resident but not elicited macrophages. Journal of Immunology, 159: 2492-2500.

38. de Fougerolles AR \& Koteliansky VE (2002). Regulation of monocyte gene expression by the extracellular matrix and its functional implications. Immunological Reviews, 186: 208-220.

39. Powell MR, Morgan J, Guarner J \& Cooley DG (1998). Cytokine mRNA levels in the hearts of inbred mice that develop different degrees of cardiomyopathy during infection with Trypanosoma cruzi. Parasite Immunology, 20: 463-471.

40. Talvani A, Ribeiro CS, Aliberti JCS et al. (2000). Kinetics of cytokine gene expression in experimental chagasic cardiomyopathy: tissue parasitism and endogenous IFN- $\gamma$ as important determinants of chemokine mRNA expression during infection with Trypanosoma cruzi. Microbes and Infection, 2: 851-866.

41. Abrahamsohn IA (1998). Cytokines in innate and acquired immunity to Trypanosoma cruzi infection. Brazilian Journal of Medical and Biological Research, 31: 117-121.

42. Aliberti JC, Machado FS, Souto JT, Campanelli AP, Teixeira MM, Gazzinelli RT \& Silva JS (1999). Beta-chemokines enhance parasite uptake and promote nitric oxide-dependent microbiostatic activity in murine inflammatory macrophages infected with Trypanosoma cruzi. Infection and Immunity, 67: 4819-4826.

43. Michailowsky V, Silva NM, Rocha CD, Vieira LQ, Lannes-Vieira J \& Gazzinelli RT (2001). Pivotal role of interleukin-12 and interferongamma axis in controlling tissue parasitism and inflammation in the heart and central nervous system during Trypanosoma cruzi infection. American Journal of Pathology, 159: 1723-1733.

44. Teixeira MM, Gazzinelli RT \& Silva JS (2002). Chemokines, inflammation and Trypanosoma cruzi infection. Trends in Immunology, 18: 262-265.

45. Alitalo K, Hovi T \& Vaheri A (1980). Fibronectin is produced by human macrophages. Journal of Experimental Medicine, 151: 602613.

46. Cofano F, Comoglio PM, Landolfo S \& Tarone G (1984). Mouse immune interferon enhances fibronectin production of elicited macrophages. Journal of Immunology, 133: 3102-3106.

47. Morris SA, Wittner M, Weiss L, Hatcher VB, Tanowitz HB, Bilezikian JP \& Gordon PB (1990). Extracellular matrix derived from Trypanosoma cruzi infected endothelial cells directs phenotypic expression. Journal of Cellular Physiology, 145: 340-346.

48. Wyler DJ, Libby P, Prakash S, Prioli RP \& Pereira ME (1987). Elaboration by mammalian mesenchymal cells infected with Trypanosoma 
cruzi of a fibroblast-stimulating factor that may contribute to chagasic cardiomyopathy. Infection and Immunity, 55: 3188-3191.

49. Machado FS, Martins GA, Aliberti JCS, Mestriner FLAC, Cunha FQ \& Silva JS (2000). Trypanosoma cruzi-infected cardiomyocytes produce chemokines and cytokines that trigger potent nitric oxidedependent trypanocidal activity. Circulation, 102: 3003-3008.

50. Savino W, Mendes-da-Cruz DA, Silva JS, Dardenne M \& Cotta-deAlmeida V (2002). Intrathymic T-cell migration: a combinatorial interplay of extracellular matrix and chemokines? Trends in Immunology, 23: 305-313.

51. Godfrey HP, Canfield LS, Kindler HL, Angadi CV, Tomasek JJ \& Goodman JW (1988). Production of a fibronectin-associated lymphokine by cloned mouse T cells. Journal of Immunology, 141: 15081515.

52. Lannes-Vieira J, van der Meide PH \& Savino W (1991). Extracellular matrix components of the mouse thymus microenvironment. II. In vitro modulation of basement membrane proteins by interferongamma: relationship with thymic epithelial cell proliferation. Cellular Immunology, 137: 329-340.

53. Leite-de-Moraes MC, Hontebeyrie-Joskowicz M, Leboulenger $F$, Savino W, Dardenne M \& Lepault F (1991). Studies on the thymus in Chagas' disease. II. Thymocyte subset fluctuations in Trypanosoma cruzi-infected mice: Relationship to stress. Scandinavian Journal of
Immunology, 33: 267-275.

54. Silva JS, Morrissey PJ, Grabstein KH, Mohler KM, Anderson D \& Reed SG (1992). Interleukin 10 and interferon $\gamma$ regulation of experimental Trypanosoma cruzi infection. Journal of Experimental Medicine, 175: 169-174.

55. Starobinas N, Russo M, Minoprio P \& Hontebeyrie-Joskowicz M (1991). Is TNF- $\alpha$ involved in early susceptibility of Trypanosoma cruzi-infected C3H/He mice? Research in Immunology, 142: 117-122.

56. Pober JS \& Cotran RS (1991). Immunologic interactions of T lymphocytes with vascular endothelium. Advanced Immunology, 50: 261302.

57. Issekutz T (1992). Lymphocyte homing to sites of inflammation. Current Opinion in Immunology, 4: 287-293.

58. Benvenuti LA, Higuchi ML \& Reis MM (2000). Upregulation of adhesion molecules and class I HLA in the myocardium of chronic chagasic cardiomyopathy and heart allograft rejection, but not in dilated cardiomyopathy. Cardiovascular Pathology, 9: 111-117.

59. Tarleton RL (2001). Parasite persistence in the aetiology of Chagas' disease. International Journal of Parasitology, 31: 549-553.

60. Andrade SG, Stocker-Guerret S, Pimentel AS \& Grimaud JA (1991). Reversibility of cardiac fibrosis in mice chronically infected with Trypanosoma cruzi, under specific chemotherapy. Memórias do Instituto Oswaldo Cruz, 86: 187-200. 